\title{
Key Determinants of Success to Achieve Sustainable Competitive Advantage (SCA)
}

\author{
Fatemeh Rezaee \\ Master student, Department of Industrial Engineering, \\ Iran University of Science and Technology, Tehran, Iran \\ Mostafa Jafari \\ Associate professors, Department of Industrial Engineering, \\ Iran University of Science and Technology, Tehran, Iran
}

\begin{abstract}
The purpose of this study is to detect the relationship among sustainable competitive advantage (SCA) and key factors affecting it, such as knowledge based view (KBV), resource based view (RBV), dynamic capability (DC) and core competencies (CC). A quantitative methodology is adopted to develop a model, and hypotheses are stated to examine the proposed relationship between the components of banking industry. A highly structured questionnaire is developed and distributed among a sample of 150 managers, specialists and consultants of bank. With a response rate of 81.3 percent, 122 questionnaires are returned; the number of valid and usable questionnaires was 101. The content validity and Cronbach's alpha was used to determine validity and reliability of questionnaire, respectively. Structural equation modeling is used to test the stated hypotheses and its model. A positive relation is found among KBV, RBV, DC, CC and SCA of Mellat Bank.
\end{abstract}

Keywords: competitive advantage, dynamic capability, resource based view, knowledge based view

\section{INTRODUCTION}

Sustainable competitive advantage has always been interesting issue in strategic management and businesses affairs. According to Porter (1985), cheap labors and natural resources are not good economy requirements. A competitive advantage is the ability obtained from resources and attributes that helps a firm to show better performance in similar industry or market than other competitors (Christensen and Fahey 1984, Kay 1994, Porter 1980 cited by Chacarbaghi and Lynch 1999). According to Barreny (1991), RBV is one of the most superior approaches to attain high levels of competitive advantage, leading to better performance through unique values which are creating a strategy that any other current or potential competitor is unable to imitate or imply it simultaneously; the used strategy cannot be duplicated for long period of time. It is suggested that resources which are tangible assets, intangible assets and capabilities, have the potential to provide firms with a sustainable competitive advantage (Barney, 1991). One of the main issues for managers to focus on is the restructuring organizational management to effectively promote the organizational knowledge. The pros argue that since knowledge based resources are usually difficult to imitate and socially complex, heterogeneous knowledge bases and capabilities among firms are the major determinants of sustained competitive advantage and superior corporate performance. As it seems, knowledge based view is a subset of source-based view, but in this challenging and changing time the source based view is considered as necessary and vital that requires to be analyzed in a single wide 
area. Defining dynamic capabilities view, the explanation of both views might be more tangible, because in new theories, dynamic capabilities view is considered as complementary of knowledge-based and source-based view.

Dynamic capabilities were first put forward by Teece et al. (1997) to explain the sources and methods of creation and captured by firms operating in rapid technological changing environments. Teece (2007) argued if the capabilities were tangible, they would be best applied. Dynamic capabilities analyze competitive advantage and performance in high speed and dynamically changing markets (Easterby and Smithetal, 2009). A competency is the capability to apply or use a set of related knowledge, skills, and abilities required to successfully perform tasks in a work setting as well as potential measurement criteria for assessing competency attainment.

However, in a further step the organization achieve different functional characteristics with combination of abilities and during activities, so that certain distinctions appear between organization to show competency of enterprises; when this competency lead to performance of enterprise beyond the industry average, values offered to customers be higher than the customer's cost, and suggestions of organization be more attractive than competitors from view point of customers, the organizations will achieve competition advantages. To dominate dynamic capabilities in organization, the concepts, elements and its sub-branches should be recognized and applied; the important one of them are source-based and knowledge-based view, both of which targeted organization resources, and with deep approach try to change it to organizational merit. Finally, concentrating acquired merits and applying them in accurate way, a sustainable competition advantage can be created for organization. Figure 1 indicates this process.

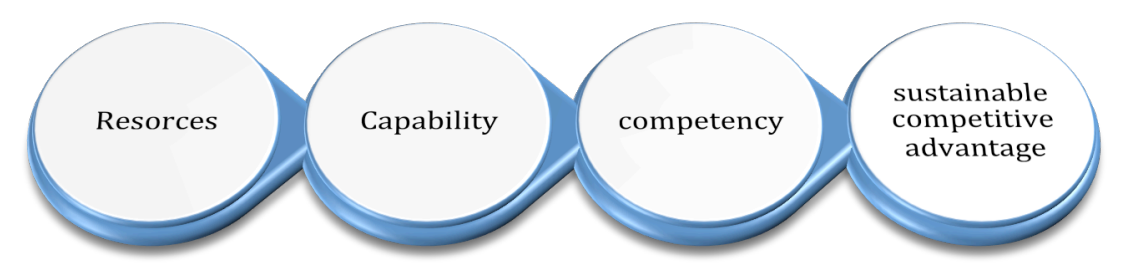

Fig. 1. Acquisition steps of Sustainable Competitive Advantage

\section{LITERATURE REVIEW AND HYPOTHESES}

In recent competitive economy era, the managerial debate on strategic management appears to reach a crucial stage. The industrial organization viewpoint is applied to the economic theory regarding the external model of industries and builds a set of economic theories that describe, explain and attempt to predict the nature of a firm in terms of its existence, behavior, structure and its relationship with the market. In strategic management the traditional model of industrial organization is criticized by the upholders of the theories that regard the resources and competencies of a firm as its principal sources of competitive advantage. One of the most recent and controversial studies pertaining to corporate strategy is known as the resourcebased view (RBV). The RBV as a basis for the competitive advantage of a firm lies primarily in the application of a bundle of valuable and tangible or intangible resources at the firm disposal. The RBV shows the accumulation of valuable, rare, inimitable and no substitutable resources is the basis of enterprise competitiveness and economic rent (Barney, 1986; Dierickx \& Cool, 
1989; Peteraf, 1993). Generally, RBV argues valuable, rare, inimitable, and non-substitutable (VRIN) resources are sources of competitive advantage (Barney, 1991). Valuable resources must enable an organization to engage a value creating strategy by either reduce its own weaknesses or superiority over its competitors (Villalonga and Amit, 2006). Newbert (2007) indicates that VRIN resources are related to capability and the capability is related to competence and the competence is related to competitive advantage. RBV should focus on the ability of the organization to sustain a combination of resources that competitors cannot possess or built up in a homological way. Any organization should in depth analyze ways to avoid imitation of their resources in order to reach capability. Finally, five resource based view dimensions including tangible assets, intangible assets, executive capability, human resource capability, and management capability were evaluated in this study.

One of the most important organizational resources is knowledge. Drucker (1993) predicted that competitive advantage in the future would be determined by knowledge resources, or what is known as knowledge workers. Consequently, both scholars and practitioners have increasingly paid great attention to an organization's ability to identify, capture, create, share or accumulate knowledge (Jang, Hong, Bock, \& Kim, 2002; Kogut \& Zander, 1996; Michailova \& Husted, 2003; Nonaka \& Takeuchi, 1995). Many researchers pointed out that knowledge would replace equipment, capital, materials and labor to become the most important element in production. However, there is no agreement among researchers about the definition of knowledge. Davenport et al. (1998) defined knowledge as "information combined with experience, context, interpretation and reflection that is ready to apply in decisions and actions." Marakas (1999) agreed that knowledge is an organized combination of ideas, rules, procedures, and information. Zeleny (2005) argues knowledge encompasses human feedback and collaborative learning. Knowledge can fall into different aspects depending on the organizational context or its under-area under; for example, technical knowledge, customer related knowledge, and product related knowledge or managerial knowledge (Barchan, 1998; Rowley, 2005; Tanriverdi, 2005, Massey et al., 2002; Collinson, 1999, Akroush 2010). Particularly in organizations the knowledge management method is very important. Knowledge management is thus a process of facilitating knowledge related activities, such as creation, capture, transformation, and use of knowledge. Knowledge management strategy has been argued to contribute to the generation of various organizational capabilities such as innovation which is vital to create an organization's capabilities and competences. Three knowledge based view dimensions including: empowering employees, promoting confidence, and coding rules focus were evaluated in this study.

Considering the existing descriptive and empirical literature, it is argued that organizational resources, or in other words, organizational KBV and RBV lead to the improvement of dynamic capability of organization. Therefore it is hypothesized that:

Hypothesis 1 . There is a positive relationship between the organizational resources and its capability.

H1a. The higher the level of organizational KBV, the higher the level of Organizational DC. H1b. The higher the level of organizational RBV, the higher the level of Organizational DC.

The strategic challenge for managers in high speed markets is to maintain sustainable competitive advantage for which dynamic capability provides such an advantage (Menon, 2008). Makadok (2001) and Kozlenkova, Samaha and Palmatier (2014) define capabilities as a special type of resource, specifically an organizationally non-transferable resource the purpose of which is to progress the productivity of the other resources possessed by the organization. 
Winter (2003) claimed it in his work and even implied as the mystery and confusion surrounding the concept of dynamic capabilities. Actually, the dynamic capabilities analyze competitive advantage and performance in high speed and dynamically changing markets (Easterby \& Smithetal, 2009). Managers must enhance their understanding of and explain organizational adaptive behavior in weathering the storm in the business environment resulting from the global financial crisis and dynamic capabilities in the context of sustainable competitive advantage and facilitate this kind of adaptive behavior (Makkonen, Pohjola, Olkkonen, \& Koponen, 2014). It has to be stated that the changing environment transforms competitive infrastructure, and dynamic capabilities effectively explain the competitive components of a firm (Teece et al., 1997; Eisenhardt \& Martin, 2000; Zollo \&Winter, 2002; Zahra, Sapienza, \& Davidsson, 2006). Lin and Wu (2014) show dynamic capabilities can mediate the firm's VRIN resources to improve performance and reach organizational competency. Mathiassen \& Vainio (2007) claimed that dynamic capabilities have been coined to capture the firm's ability to adapt to unpredictable and changing environments. They allow the firm to reconfigure its resources and respond to market changes effectively. Foerstl et al. (2010) described that general dynamic capabilities will differ from company to company. It has to be stated that they have common features even when they implement in different firms but might be idiosyncratic in their specific form. Eisenhardt, and Jeffery (2000) argued that dynamic capabilities are a set of specific and identifiable processes such as product development, strategic decision making, and alliancing. Consequently, the dynamic capability view discuses origination, process, contributions, and the effects of dynamic capabilities (Zollo \& Winter, 2002; Zahra et al., 2006; Wang \& Ahmed, 2007; Helfat \& Peteraf, 2009; Lin \& Wu, 2014). This study provides four dynamic capability dimensions: sensing, learning, reconfiguration, and coordination based on the studies carried out by Teece (2007) and Menon (2008). The implementation of dynamic capabilities leads to better competence to be achieved as the consequence of achieving organizational competence. Hence, the second hypothesis is followed:

Hypothesis 2. The higher the level of organizational DC, the higher the level of organizational core competencies (CC).

A large and growing body of literature is available on core competencies and their role in increasing the firm's competitive advantage (Srivastava, 2005). It is expected that academics, consultants and business executives support understanding of competence and dynamic competitive advantage by developing normative and theoretical preposition (Bogner et al, 1999). Further studies show that core competency and competitive advantage are not quite the same but it should not be overlooked that a successful competitive strategy is based on both concepts of core competence and competitive advantage (Javidan, 1998). Leonard-Barton defines core competence as a knowledge set that differentiates a firm and creates a competitive advantage (Leonard-Barton, 1992). Core competence can be considered as the base of a firm's competitive advantage; vast majority of markets can implement it for their future products when it refers to a specific knowledge for defining and solving problems (Srivastava, 2005). A successful company should focus on its core competence and invest in the development of activities creating value and achieve core competence that is the source of competitive advantage. Core competence is considered as a fundamental concept for competitive strategy in a highly competitive market which is identified as knowledge set helping a company to perform in a different way from competitors and results in a competitive advantage. The core competence concept has been applied by the organization to identify and efficiently utilize its power. Gupta et al., (2009) further argued that core competence is a collection comprised of communication, involvement and a deep commitment across 
organizational boundaries. Ljungquist (2008) demonstrated the core competence has been developed to justify business diversity at large companies and support some internal processes such as product development. Bani-Hani \& AL-Hawary (2009) further showed that a positive relationship exists between core competences and competitive advantage.

In the light of the above discussions, it is proposed that competency has positive effects on all the different types of SCA. In this respect, CC plays the role of mediator variable that carries the positive effects to the various aspects of SCA. Accordingly, the basic hypothesis on the relationship between CC and SCA is as follows:

Hypothesis 3. There is a positive relationship between the organizational CC and all the different types of SCA.

H3a. The higher the level of organizational CC, the higher the level of sustainable competitive advantage of market oriented (SCAM).

$\mathrm{H} 3 \mathrm{~b}$. The higher the level of organizational CC, the higher the level of sustainable competitive advantage of oriented (SCAC).

H3c. The higher the level of organizational CC, the higher the level of centered sustainable competitive advantage of finance oriented (SCAF).

Although there are many different viewpoints on theories as RBV, KBV, DC, they are all similar in that to maximize the organizational competitive advantage and improve the organization's position among their competitors. There is debate on how organizations could reach to sustainable competitive advantage. Also many experts have revealed their opinions for such a matter, such as Porter who believed the cheap labors and natural resources are not good economy requirements (Porter 1985 sited by Andersen, 2013). He expressed that a competitive advantage is the ability obtained through resources and attributes that helps a firm to perform at a higher level than the other competitors in the same industry or market (Chacarbaghi and Lynch, 1999 sited by Josiah, 2013). When a firm has reached a competitive advantage and prevents imitation by competitors, destructing competitor behavior and achieving sustainable competitive advantage is considered as an obvious result. However preventing imitation is not permanent; the firm should make any effort to delay this occurrence to gain the maximum benefit from its competitive advantage (Reed and Defillippi, 1990; Pearce and Robinson, 2000; Christensen, 2001; Chunxia, 2012). Barney argued that a firm has a competitive advantage when implies a value creating strategy while any current or potential competitors are deprived to implement the strategy simultaneously and they are also not capable of duplicating that (Barney, 2000). Trung (2014) believed that a strategic position of a companies' management is foreseeing the market trend and obtaining sustainable competitive advantage to improve companies' position among competitors.

It may be said that important subject in a competitive advantage concept is the question of what are the possible signs of a competitive advantage; in other words what are the measures showing that a company has reached a competitive advantage. According to the literature review and experts views on the subject, the mentioned measures have been classified into three categories comprised of market, finance and customer. A sustained competitive advantage is obtained through unique values which are creating a strategy that any other current or potential competitor is unable to imitate or imply it simultaneously and finally the using strategy cannot be duplicated for long period of time.

Customer: core competence which is defined as a skill enabling an organization to create a fundamental value and lead to customer loyalty should result in customer perceived value. 
Studies show that customer loyalty and customer attention are two challenging concepts for all organizations. It is clear that loyal customers can raise sales and customer share and reduce costs and higher prices (Alrubaiee and Alnazer, 2010). As a result our study seeks to address two critical dimension of competitive advantage with a focus on customers: flexibility and responsiveness. Flexibility refers to organization capabilities to provide a superior customer value (Johnson, Scholes and Whittington, 2008) and responsiveness is defined as the ability of an organization to respond fast to their customers' requirements (Carlos, Sousa and Fernando, 2010). A competitive advantage can be obtained through meeting organizational goals and customer needs in a highly competitive environment (Evans et al., 2006). Therefore organizations should compete with each other for taking customer attention. In other words a competitive advantage is reached when customer demands are met more effectively and efficiently than their competitors as long as possible; therefore their competitors make attempt to duplicate, reproduce and even surpass the competitive advantage.

Market: Li and Zhou (2010) investigate how market orientation and managerial tie can impacts competitive advantage. This research indicated that one of the most important dimensions of a firm's competitive advantage is institutional advantage which means an organization's superiority in obtaining rare sources and institutional support. In this context it is stated that brands and corporate images have significant impact on sustained competitive advantage required for a highly competitive environment (Seetharaman, Nadzir and Gunalan, 2001; Amini, 2012).

Finance: Achieving a competitive advantage leads a company to reach and sustain above average profitability for some years (jones and Hill 2013). Profit is gained through sales incomes resulted from customer purchase (Rijamampianina, Abratt, February, 2003; Thompson et al., 2012).

It can be argued that the financial performance, which is the combination of the achievements in performance indicators such as profit rate is higher than the industry average; increasing the efficiency in financial processes and saving costs is the final goal of banking industry that is positively affected by the market and customer performance.

Hypothesis 5. Higher market and customer performance improvement results in improved finance performances.

H5a. The greater the customer performance improvement, the greater the finance performance improvement.

H5b. The greater the market performance improvement, the greater the finance performance improvement.

Derived from the existing literature, the proposed relationships among resources and sustainable competitive advantage are discussed and hypotheses related to these variables are developed. The research framework generated in this study is illustrated in Fig. 2. This framework briefly proposes that the RBV, KBV. DC and CC will enhance SCA, which will then improve customer, market and finance performances. 


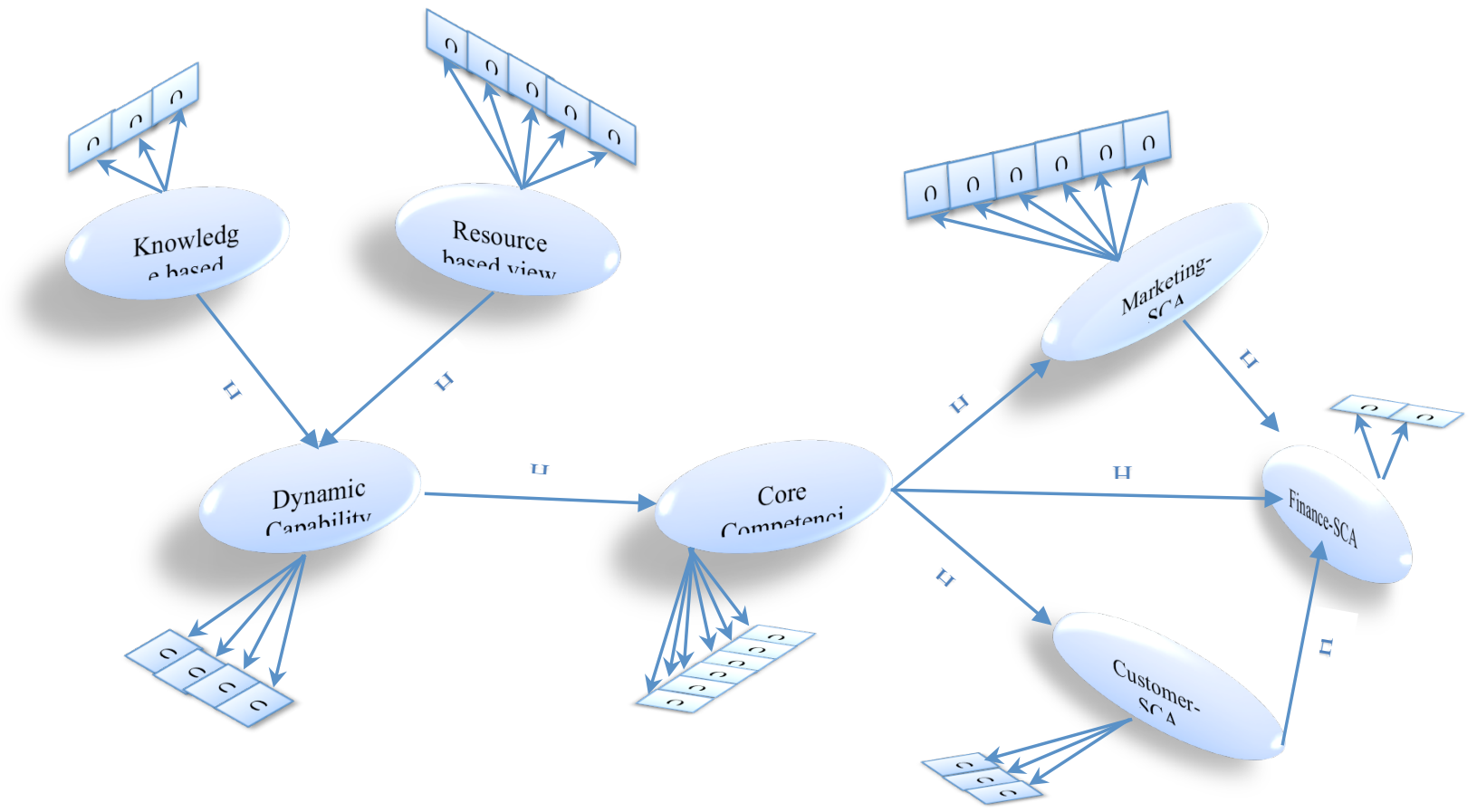

Fig. 2. Conceptual model between SCA and key factors affecting on its

\section{METHODOLOGY}

In this section, the sample, procedures of data collection, operational measures of variables and statistical analyses are studied in order to determine the links among the concepts of KBV, RBV, DC, CC and SCA.

\section{Sample and procedures}

The banking industry is a major part of Iran's economy. After the study of performance statistics on Iranian banks, interviews were conducted with expert academics in the banking industry and 50 of the deputy and directors of Iran banks. After all statistical studies and discussions, Mellat Bank of Iran (MBI) was chosen as case study because of the implementation of appropriate strategies in maintaining and enhancing its competitive advantage among other Iranian banks. The study shows that MBI has found the competitive advantage among their competitors in recent years. According to the Bank reportage of Iran annually, Mellat bank is superior to competitors in terms of finance, customer and market; and this superiority has continued over the recent years. Here, the study attempts to investigate this practical success in the context of an empirical study. Following the investigations conducted different strategies, these advantages are achieved. MBI has considerable growth in the competition with rival, turned a suitable locale for research to examine the influence of tie concepts in the banking industry.

As an effort to ascertain the content validity of the survey questionnaire, a draft survey was pre-tested by both academicians (i.e. two strategic management assistant professors) and practitioners (i.e. ten bank managers). The participants were requested to evaluate the survey questionnaire on its wording, clarity and relevancy. Ultimately, the final version of questionnaire was distributed randomly to the executors or senior managers, specialists and consultants from the administration and improvement methods, marketing, strategy, risk management and operational management department of MBI. The sample was chosen based on their knowledge on study specific issues. Sample size was limited by calculation method of Cochran sample size and using community correction coefficient. Due to high amount of questions, the respondents were asked to respond in 4 steps. 
From the total of 150 questionnaires, 122 were returned with complete answers, which represent a response rate of $81.3 \%$. The number of valid and usable questionnaires was 101 . Fig.3 shows the company characteristics and the target respondents. In this figure it is indicated that the majority of respondents (81.1 percent) are males that is consistent with the Iranian society which still is relatively male dominated especially in the top management positions. The majority of managers are middle-aged and well educated. This is consistent with the Iranian society that is described as middle-aged and enjoys high levels of education in the bank department. Being well educated would greatly help MBI in building and accumulating DC to reach SCA now and in the future. Moreover, Fig.3 shows that the majority of managers (67 percent) is well experienced in this industry with more than ten years of experience. This holds a strategic implication that indicates MBI has relevant and sufficient business industry experience that is crucial for building and sustaining assets and capabilities as a source of competitive advantage. Finally, figure 3 shows that 61.6 percent of managers have business education background which indicates there is reasonable recruitment process in the bank that focus on quality of people as one of their major assets to achieve success.

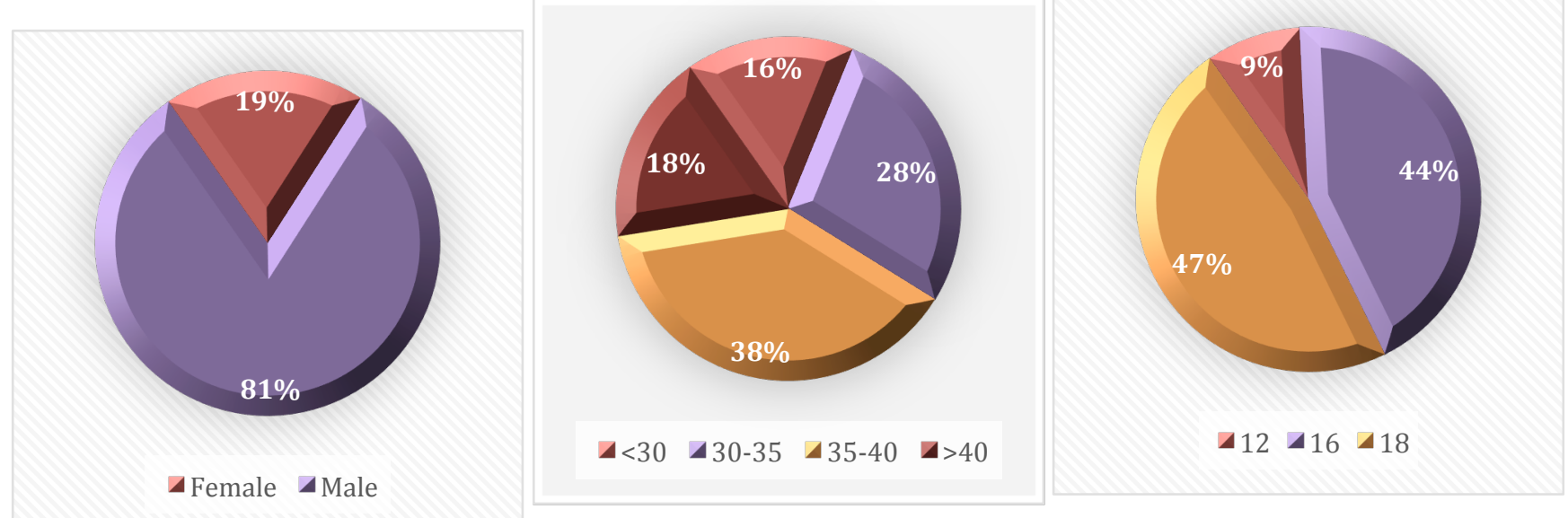

Gender

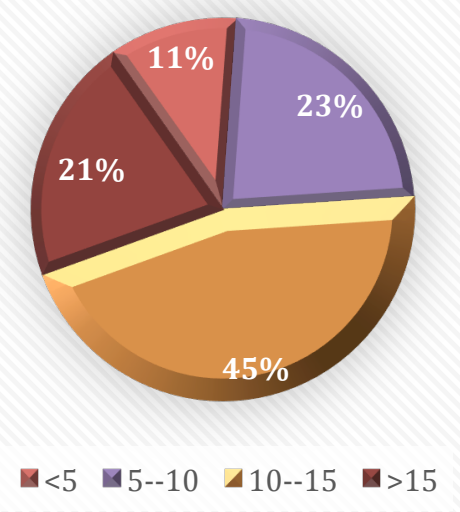

Job experience
Age

Years of education

\section{Measurement}

This part is organized into five sections that present how to measure the dimension of each construct. In order to assess the precision and focuses of the respondents, some questions were designed negatively.

\section{Resource based view (RBV)}

Five resource based view dimensions were evaluated in this study including tangible assets, intangible assets, executive capability, human resource capability, management capability. 
These RBV dimensions were selected based on the studies of Barney (1999). Each of these RBV practices was measured by Likert scale ranging from strongly disagree $=1$ to strongly agree $=5$.

\section{Knowledge based view (KBV)}

Three knowledge based views were evaluated in this study dimensions including empowering employees, promoting confidence, coding rules focus. These KBV dimensions were selected based on the studies carried out by Bhatt (2002). Each of these KBV practices was measured by Likert scale ranging from strongly disagree $=1$ to strongly agree $=5$.

\section{Dynamic capability (DC)}

Four dynamic capabilities dimensions were evaluated in this study including sensing, learning, reconfiguration, and coordination focus. These dynamic capabilities dimensions were selected based on the studies of Teece (2007) and Menon (2008). Each of these dynamic capabilities practices was measured by Likert scale.

\section{Core Competencies (CC)}

These core competencies questions were selected based on the studies of Javidan (1998) and Srivastava (2005). Each of these core competencies practices was measured by Likert scale.

\section{Sustainable Competitive Advantage (SCA)}

The SCA has been used to assess various competitive advantage settings. Therefore, the three area of SCA were chosen to represent the SCA dimensions in the present study. Reviewing the studies concerning the sustainable competitive advantage in service institutions such as banks found that most of the studies assessed the construct of service institutions from the market, costumer and finane view. Each of these SCA practices was separately measured and analysis. In order to measure respondents' perception towards the SCA within bank, a 5-point Likert scale was developed ( 1 = strongly disagree; 5 = strongly agree).

\section{STATISTICAL DATA ANALYSIS}

In this study, a Structural Equation Modelling (SEM) was used on the multi-item measures. In order to perform the SEM technique, data analysis was performed in four steps:

Checking normality assumption: prior to the analysis of the data the normality assumption was used. One of the main functions includes checking multivariate normality to determine if a data set is well modelled by a normal distribution.

Factor Analysis: consists of two parts, the Kaiser-Meyer-Olkin (KMO) and Bartlett's Test, and exploratory factor analysis. Statistical data analysis should always raise question such as: Is the relationship among variables strong enough? Is it a good idea to precede a factor analysis for the data? Factor Analysis can reply to these questions with KMO and Bartlett's Test. The Kaiser-Meyer-Olkin (KMO) measure of sampling adequacy tests whether the partial correlations among variables are small. The Kaiser-Meyer-Olkin measure of sampling adequacy is an index for comparing the magnitudes of the observed correlation coefficients to the magnitudes of the partial correlation coefficients. Another indicator of the strength of the relationship among variables is Bartlett's test of sphericity. Bartlett's test of sphericity tests whether the correlation matrix is an identity matrix; that will indicate the factor model is appropriate. This test is used to test the null hypothesis that the variables in the population correlation matrix are uncorrelated. In order to separate the dimensions of each construct, Exploratory Factor Analysis (EFA) performed with varimax rotation. 
Confirmatory factor analysis (CFA): is performed to evaluate the overall measurement model. In order to evaluate the validity of measurement model, convergent and discriminant validity were evaluated. Convergent validity, along with discriminant validity, is a subtype of construction validity. Convergent validity can be estimated using correlation coefficients. Convergent validity is concerned with the degree that the both assessments of constructs theoretically and actually should be related (Campbell 1959). A successful evaluation of convergent validity shows that a test of a concept is highly correlated with other tests designed to measure theoretically similar concepts.

Examining the hypotheses through SEM: methodologically, the formulated hypotheses were measured and tested using SEM approach. This method proved to be far more superior to regression analysis. Firstly, SEM approach supplies statistical competency and provides a definite method to deal with multiple relationships simultaneously, while multiple regression analysis does not. Secondly, as SEM is capable of testing the relationships comprehensively, it has moved from exploratory factor analysis to confirmatory factor analysis. Thirdly, the unobserved concepts and the measurement error in the estimation process are also taken into the account with the use of the SEM practice (Kline, 2005). Given the many advantages of SEM, coupled with the support of many researchers stating that such an approach is a useful methodological assessment tool for many measurement models (Bollen, 1989), SEM was chosen to test the structural relationships between the seven constructs of KBV, RBV, DC, CC, SCAM, SCAC, and SCAF.

\section{Test Results}

Prior to the analysis of the data, the normality assumption is used in the data preparation stage. One of the main functions includes checking multivariate normality to determine if a data set is well modeled by a normal distribution. Normality test was achieved through skewness $< \pm 2$ and kurtosis $< \pm 2$. In This study, the amounts of skewness and kurtosis were the ranges. However, these ranges may be considered smaller or larger by different scientists of statistics. Furthermore, the Shapiro-Wilks tests were also used to verify the existence of normality; the null-hypothesis of this test is that the data are normally distributed and if the pvalue is more than the chosen alpha level (i.e. 0.05), then the null hypothesis is accepted, there is evidence that the tested data are normally distributed. The result revealed the normal distribution of the data since the $\mathrm{p}$-value is greater than 0.05 . The $\mathrm{p}$-value in this study is more than 0.05 , thus the model satisfactorily fits a normality distribution (Razali and Wah, 2011).

The KMO measures the sampling adequacy which should be greater than 0.5 for a satisfactory factor analysis to precede. According to table 1 , the KMO measure is $0.814,0.865,0.794$ and 0.820 for KBV, RBV, DC and SCA, respectively. Large values for the KMO measure indicate that factor analysis of the variables is suitable. From the same table, we can see that the Bartlett's test of sphericity is significant. That is, its associated probability is less than 0.05 . In fact, it is actually 0.000. It is small enough to reject the hypothesis. This means that the correlation matrix is not an identity matrix. It is concluded that the relationship among variables is strong. It is a good idea to proceed an exploratory factor analysis for the data.

In the course of the validation process, some items were found to have unacceptably low factor loadings less than 0.5 on their respective unobserved hypothetical or latent variable, which were subsequently removed. The internal reliability is evaluated scales by Cronbach's alpha (C$\alpha$ ). The result has shown that the Cronbach's alpha value ranges between 0.765 to $0.953,0.815$ to 0.940 and 0.762 to 0.922 for $\mathrm{KBV}, \mathrm{RBV}$ and DC factors, respectively, and 0.844 for SCA of market centered, 0.777 SCA of customer centered and 0.717 for finance centered indicating 
according to Nunnally and Bernstein (1994), the measurement of the variables are well above the acceptable threshold of 0.70 .

A convergent validity has been tested by assessing factor loadings which should be significant and exceed 0.5 , composite reliabilities (CR) which should exceed 0.7 , and the average variance extracted (AVE) that should be more than 0.5 for all constructs (Fornell \& Larcker, 1981). In our model, all the factor loadings and composite reliabilities fall in the acceptable ranges and are significant at the 0.001 level. Factor loadings ranges from 0.52 to $0.98,0.59$ to 1.00 , and 0.52 to 0.98 and 0.52 to 0.94 , composite reliabilities (CR) range from 0.762 to $0.922,0.857$ to $0.955,0.762$ to 0.922 and 0.703 to 0.851 , AVE ranges from 0.522 to $0.860,0.547$ to 0.835 , 0.522 to 0.860 and 0.556 to 0.659 for KBV, RBV, DC, and SCA, respectively. The results show that the model meets the convergent validity criteria. Table 1 shows the means, SD, factor loading, AVE, CR and C- $\alpha$ of every constructs. Convergent validity can be established if two similar constructs correspond with one another, while discriminant validity applies to two dissimilar constructs that are easily differentiated. A successful evaluation of discriminant validity shows that concept test is not highly correlated with other tests designed to measure theoretically different concepts (Kline, 2005). Fornell and Larcker's approach has been used to assess discriminant validity. In this approach, the AVE for each construct should be higher than the squared correlation between the construct and any of the other constructs. Table 2 indicates the measurement model has satisfactory discriminant validity. In Table 3, diagonal elements in italics are the AVE and off-diagonal elements are the squared correlations between constructs. It is obvious that each diagonal element is higher than respective off-diagonal elements. Therefore, all constructs in the measurement model were judged as having adequate discriminant validity.

Table 1: Results of CFA and internal reliability testing \& K-M-O measure

\begin{tabular}{|c|c|c|c|c|c|c|}
\hline Factors & Mean & SD & Loading & AVE & CR & $\mathbf{C}-\boldsymbol{\alpha}$ \\
\hline Factor 1: (empowering employees) & & & & & 0.54 & 0.82 \\
\hline \multicolumn{7}{|l|}{0.823} \\
\hline \multicolumn{7}{|l|}{ _ has made it possible for employees to apply their } \\
\hline Individual experiences they have had during their work & 3.65 & 0.888 & 0.77 & & & \\
\hline \multicolumn{7}{|l|}{ _ has provided a condition in which responsible and } \\
\hline Aware employees may turn their ideas into reality & 3.58 & 0.941 & 0.67 & & & \\
\hline \multicolumn{7}{|l|}{ _ maintains that employee training which is related to } \\
\hline \multicolumn{7}{|l|}{ Employee performance, job processes and professions } \\
\hline Is a most significant function of an organization & 3.64 & 0.916 & 50.75 & & & \\
\hline \multicolumn{7}{|l|}{ _ has not provided appropriate trainings by which } \\
\hline Employees may realize the business camouflaged reality & 3.53 & 0.819 & 0.74 & & & \\
\hline \multicolumn{7}{|l|}{ _try to revive and accomplish knowledge-based } \\
\hline Concepts by using knowledge-led team & 3.46 & 0.954 & 0.98 & & & \\
\hline \multicolumn{7}{|l|}{ _ is becoming more empowered by holding scientific and } \\
\hline Knowledge-led meetings & 3.29 & 0.887 & 0.90 & & & \\
\hline \multicolumn{7}{|l|}{ _ surveys problems and detects the best solution regarding } \\
\hline Employee commitment by making participation & 3.38 & 0.906 & $5 \quad 0.73$ & & & \\
\hline
\end{tabular}


Factor 2: (promoting confidence and motivation of employees)

0.765

_ has believed that employee behavior with customers is one

Of the evaluating factors requiring for their competency

_ is able to fulfill expert needs and can encourage

And reward them

_the experts and qualified and smart people are

Not free for what they want to do

_ has got balance between organizational rules and

Requirements, and employee creativity and risk taking

_ holds discussion and brainstorm meetings to improve

Employee communications

_ let's people revise what they think about each other by

Having knowledge-led conferences

Factor 3: (coding rules)

0.953

_ clarifies rules and procedures to prevent employee

Multi-faceted understandings

_ reviews all prescriptions throughout the entire

Organization as the environment changes

$\begin{array}{lll}3.14 & 0.898 & 0.95\end{array}$

$\mathrm{K}-\mathrm{M}-\mathrm{O}$ measure of sampling adequacy $=0.814 ;$ Bartletttestofsphericity $=928.983 ; \mathrm{p}<0.000$.

Factor 1: (tangible assets)

0.940

_ may provide variety of services in both aspects of currency

and monetary

$\begin{array}{lll}3.32 & 1.07 & 0.95\end{array}$

_ enjoys having a good self-banking services such as POS

and ATM

$\begin{array}{lll}3.39 & 1.05 & 0.93\end{array}$

_ has not been successful in the field of investment

such as stocks, deposits, and facilities

$\begin{array}{lll}3.18 & 1.11 & 0.97\end{array}$

_ is a leading financial institution among all the banks

of the country in the field of market, for example

how many accounts and customers it has

$\begin{array}{lll}3.32 & 1.07 & 0.99\end{array}$

_ is barely considered as a strong institution in terms

of infrastructure such as IT and software and

hardware systems

$3.25 \quad 1.14 \quad 0.59$ 
Factor 2: (intangible assets)

0.907

_ it has a huge information data base and it is strong in

the field of information and communication

$\begin{array}{lll}3.57 & 1.04 & 0.81\end{array}$

_ has involved trained, empowered, and responsible

employees

_ has an organizational identity and there is a clear

Coordination between internal and external image

of the bank

$\begin{array}{lll}3.41 & 1.05 & 0.86\end{array}$

_has strategic programs in order to create ideas

and innovation

_ is equipped with the swift network hardware and software

and also it is a member of it

_ has not been able to successfully make customer satisfaction

and make reliability and quick response as well

$\begin{array}{lll}3.44 & 0.96 & 0.72\end{array}$

_ is in a high position regarding credit and population

$\begin{array}{lll}3.41 & 1.05 & 0.74\end{array}$

Factor 3: (executive capability)

0.923

_has appropriately provided qualified services

and new service development

_ has reached intersectional coordination,

cooperation, and codirecting through all its

managerial and operational levels

_ has created a service and customer-oriented and

innovative organizational culture which is quite

compatible with market changes

_ has the a distinctive ability to deliver quality services

has assumed that creativity, innovation, and cost

saving in the business is a part of its research

and development process

$\begin{array}{lll}3.54 & 0.94 & 0.86\end{array}$ 
Rezaee, F. \& Jafari, M. (2016). Key Determinants of Success to Achieve Sustainable Competitive Advantage (SCA). Archives of Business Research, $4(6), 351-375$

Factor 4: (human resource capability)

0.815

_has involved responsible employees with the ability

of quick responding to customers

has made it possible for employees to have the

chance to apply their skills, abilities,

capabilities, and knowledge

$\begin{array}{lll}4.20 & 0.75 & 0.70\end{array}$

does not provided organizational learning which

encourage employees to learn more

_ has created an environment in which employees

can have teamwork and cooperate together

_does not have efficient skills regarding social capability

like teamwork and communication

$\begin{array}{lll}3.78 & 0.90 & 0.82\end{array}$

Factor 5: (management capability)

0.930

_ has spread knowledge and organizational experiences

through all its sectors and tries to update them

_ has unified all the visions and managerial thoughts

through all its senior management

$\begin{array}{lll}3.90 & 0.87 & 0.77\end{array}$

_ has built a flexible culture by which it has the ability

to adapt with unexpected changes and other's ideas

$\begin{array}{lll}4.14 & 0.80 & 0.92\end{array}$

_ senior managers have enough managerial skills and

a real leadership is established in the organization

$\begin{array}{lll}4.12 & 0.86 & 1.00\end{array}$

$\mathrm{K}-\mathrm{M}-\mathrm{O}$ measure of sampling adequacy $=0.865 ;$ Bartletttestofsphericity $=2643.219 ; \mathrm{p}<0.000$. 
Factor 1: (sensing)

0.798

Understanding customer needs and market dynamics

_Realizing environmental signals and information

_Reacting quickly and appropriately to all information

Received from market

Factor 2: (learning)

0.765

_Releasing information quickly and in time

_Detecting, verifying, employing, and applying new

Solutions

_Generating new ideas and giving them the chance

To be real

Factor 3: (reconfiguration)

0.853

_Combining some services into one new service and

For using that one again

$\begin{array}{lll}2.99 & 1.15 & 0.71\end{array}$

_Rotating internal resources such as job rotation

For employee

$3.14 \quad 1.03 \quad 0.81$

_Making appropriate resource configuration

In order to respond to environment changes

_Creating innovation and new solutions in decision

Making pro

_Maintaining wise managers who believe in cooperation

And performing such activities involved cooperation

$\begin{array}{lll}3.04 & 0.95 & 0.64\end{array}$

_Knowledge distribution, allocation, and finally

Knowledge sharing

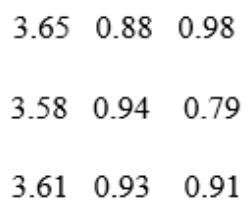

$\begin{array}{lll}3.53 & 0.82 & 0.81\end{array}$

$\begin{array}{lll}3.46 & 0.96 & 0.80\end{array}$

$\begin{array}{lll}3.64 & 0.84 & 0.52\end{array}$ 
Factor 4: (coordination)

0.805

_Putting right people on right places while they are

cooperating with each other

$\begin{array}{lll}3.53 & 0.96 & 0.79\end{array}$

_ cooperating and effectiveness of different sources

$\begin{array}{lll}3.44 & 0.81 & 0.64\end{array}$

_Giving efficient, flexible and high-quality services

$\begin{array}{lll}3.55 & 0.98 & 0.71\end{array}$

$\mathrm{K}-\mathrm{M}-\mathrm{O}$ measure of sampling adequacy $=0.794 ;$ Bartletttestofsphericity $=957.257 ; \mathrm{p}<0.000$.

Factor 1: (market)

0.844

_Integrate performances to find the highest position

among all competitors

Focusing on market growth and market share indicator

_Successful in effective in the market

_Providing a socially complicated environment which

it is difficult for competitors to imitate

_Fully committing to the society and tries to create value

for that

_Integration and re-formulation of services and create

new services faster than competitors

Factor 2: (customer)

0.777

_Attractive offers the customers are not superior

compared to competitors

_Providing efficient services with quality and flexibility

_ Investing in customer loyalty and satisfaction and

create a positive impression 
Factor 3: (finance)

0.717

_Profit rate is higher than the industry average

$\begin{array}{lll}3.30 & 0.922 & 0.58\end{array}$

_Increasing the efficiency in the financial processes

and save costs

$\begin{array}{lll}3.60 & 0.99 & 0.97\end{array}$

$\mathrm{K}-\mathrm{M}-\mathrm{O}$ measure of sampling adequacy $=0.820 ;$ Bartletttestofsphericity $=440.401 ; \mathrm{p}<0.000$.

Table 2: Discriminant validity analysis

\begin{tabular}{|c|c|c|c|c|c|c|c|c|}
\hline Factors (KBV) & SEN & & LEA & & REC & \multicolumn{3}{|c|}{$\mathrm{COR}$} \\
\hline$\overline{\text { SEN }}$ & 0.860 & & & & & & & \\
\hline LEA & 0.336 & & 0.523 & & & & & \\
\hline REC & 0.116 & & 0.160 & & 0.510 & & & \\
\hline $\mathrm{COR}$ & 0.325 & & 0.449 & & 0.160 & & 0.6 & \\
\hline Factors (RBV) & TA & ITA & & $\mathrm{HRC}$ & & $\mathrm{EC}$ & & $\mathrm{MC}$ \\
\hline$\overline{\mathrm{TA}}$ & 0.807 & & & & & & & \\
\hline ITA & 0.129 & 0.746 & & & & & & \\
\hline HRC & 0.062 & 0.518 & & 0.832 & & & & \\
\hline EC & 0.067 & 0.562 & & 0.260 & & 0.547 & & \\
\hline $\mathrm{MC}$ & 0.026 & 0.221 & & 0.102 & & 0.115 & & 0.835 \\
\hline Factors (DC) & SEN & & LEA & & REC & & COR & \\
\hline$\overline{\text { SEN }}$ & 0.860 & & & & & & & \\
\hline LEA & 0.336 & & 0.523 & & & & & \\
\hline REC & 0.116 & & 0.160 & & 0.510 & & & \\
\hline $\mathrm{COR}$ & 0.325 & & 0.449 & & 0.160 & & 0.662 & \\
\hline Factors (SCA) & SCAM & & SCAC & & $\mathrm{SCAF}$ & & & \\
\hline$\overline{\text { SCAM }}$ & 0.503 & & & & & & & \\
\hline SCAC & 0.176 & & 0.556 & & & & & \\
\hline SCAF & 0.250 & & 0.231 & & 0.659 & & & \\
\hline
\end{tabular}

\section{The structure model}

Fig. 2 exemplifies the proposed structural model showing the association among the seven dimensions of KBV, RBV, DC, CC, SCAM, SCAC, and SCAF, respectively. To examine the model, conventional maximum likelihood estimation approaches were used. Fig. 4 summarizes main findings of SEM analysis. It assessed the measurement model fit by evaluating: (1) absolute fit indices including observed normed $\chi 2$ ( $\chi 2 / d f)$, goodness of fit index (GFI), adjusted goodnessof-fit index (AGFI) and adjusted goodness-of-fit index (AGFI); (2) Comparative fit indices including normed fit index (NFI), and comparative fit index (CFI); and (3) parsimonious fit indices including parsimony goodness-of-fit index (PGFI) and parsimony normed fit index (PNFI) and the root mean square error of approximation (RMSEA). The summary results of 
the structural equation modeling technique are shown in Table 5. Examples of the fundamental measures are the ratio of $\chi 2$ statistics to the degree of freedom (df), normed fit index (NFI), comparative fit index (CFI), goodness-of-fit index (GFI) and the root mean square error of approximation (RMSEA). Table 5 summarizes the results of CFA models, all the model-fit indices are well above their common acceptable levels in which $\chi 2 / \mathrm{df}$ was less than 3.0 and greater than 0.90 for GFI, AGFI, CFI and NFI as suggested by Bagozzi and Yi (1988), with RMSEA less than 0.08 according to Browne and Cudeck (1993), suggesting that the CFA models fit well. In their studies, Anderson and Gerbing (1988) suggest that values greater than 0.90 are desired for GFI, CFI, AGFI, and NFI while Browne and Cudeck (1993) required values less than 0.08 for RMSEA. Based on Table 5, the ratio of $\chi 2$ statistics to the degree of freedom for our model was 2.8. The value of the remaining fit indices include the GFI = 0.96; $\mathrm{AGFI}=0.91 ; \mathrm{CFI}=$ 0.94; NFI $=0.95$; and RMSEA $=0.072$. All the model-fit indices are well above their common acceptable levels, suggesting that the structural model fits well. It can be concluded that a goodness-of-fit exists for the measurement scale of market orientation. Fig. 4 shows the standardized path diagram of T-values for the structural model. Therefore, we can conclude that the model fits the data well and thus is able to explain the research hypotheses

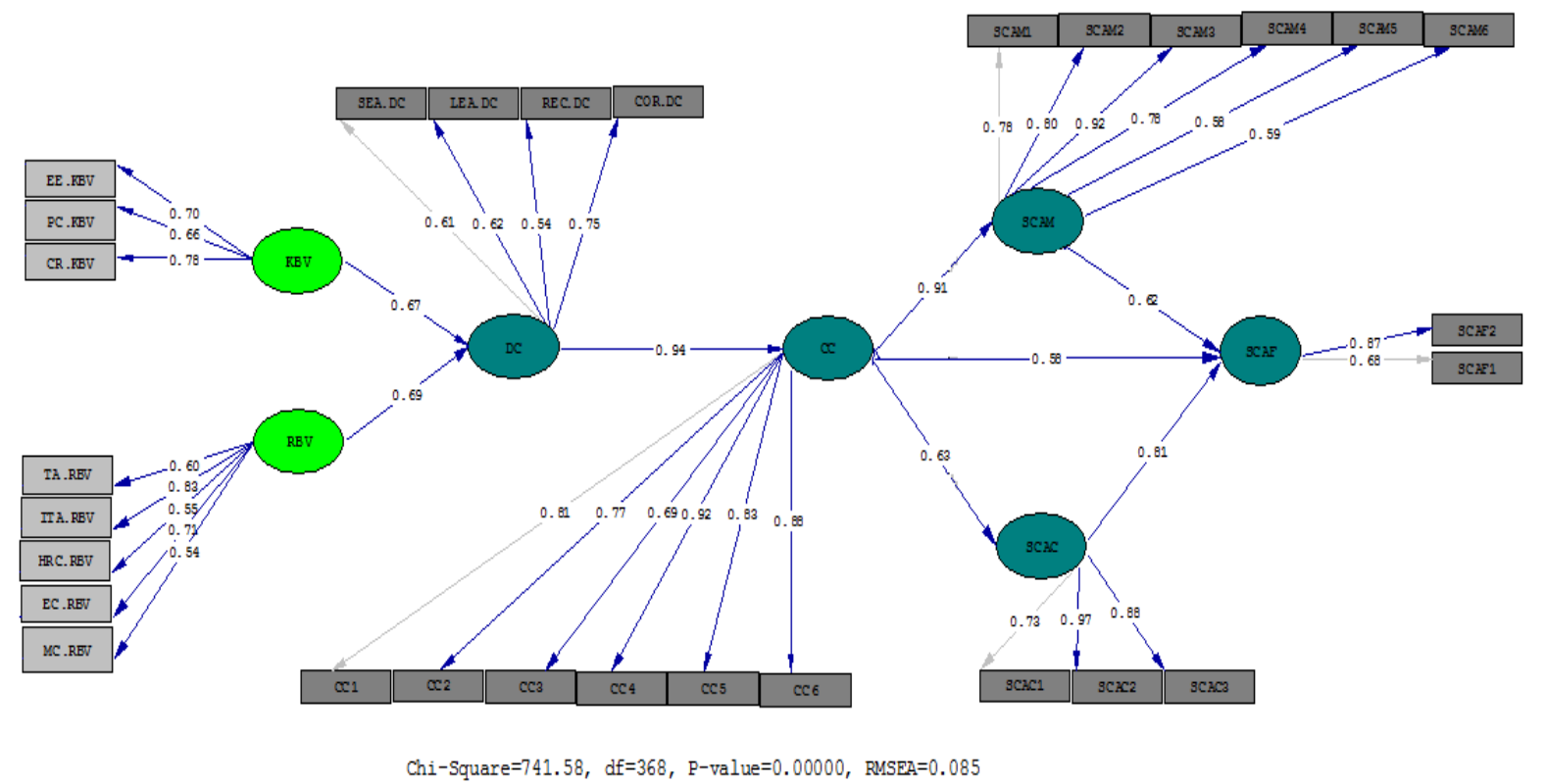

Fig. 4. Structural Relationship model between SCA and key factors affecting on its 


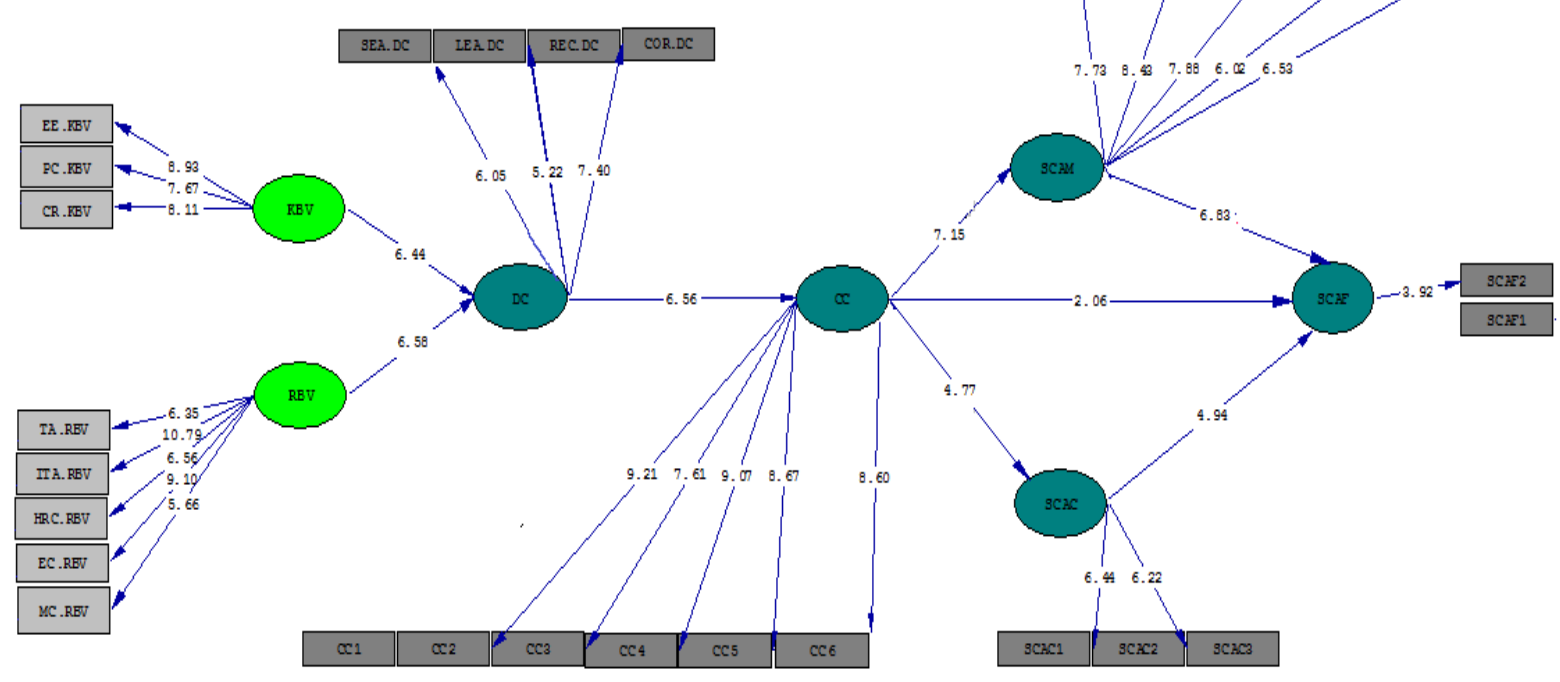

Chi-Square $=741.58, d f=368, \mathrm{P}-\mathrm{value}=0.00000, \mathrm{RMSEA}=0.085$

Fig. 5. T-value model between SCA and key factors affecting on its

Table 3: Overall fit indices of the CFA model

\begin{tabular}{lll}
\hline Fit index & Scores & Recommended cut-off value \\
\hline Absolute fit Indices & 2.67 & $\leq 3$ \\
$\mathrm{X}^{2} / \mathrm{df}$ & 0.93 & $\geq 0.9 ; \geq 0.8$ \\
GFI & 0.91 & $\geq 0.9 ; \geq 0.8$ \\
AGFI & & \\
Comparative fit Indices & 0.92 & $\geq 0.9$ \\
NFI & 0.96 & $\geq 0.9$ \\
CFI & & \\
Parsimonious fit Indices & 0.06 & $\leq 0.08 ; \leq 0.1$ \\
RMSEA & 0.87 & The higher, the better \\
PGFI & 0.95 & The higher, the better \\
PNFI & &
\end{tabular}

\section{Hypothesis testing}

In the hypothesis testing stage, the proposed hypotheses were examined using the Structural Equation Modelling (SEM) technique. The findings (Table 5) for H1a (KBV to DC, $\gamma 11=0.67 ; \mathrm{p}$ $<0.000$ ) and for H1b (RBV to DC, $\gamma 11=0.69$; $\mathrm{p}<0.000$ ) imply that KBV and RBV have the positive and significant relationship with DC in Mellat bank. By adopting two theories of knowledge based view and resource based view, firms will be better able to improve the level of dynamic capability through a more systematic approach. This result is consistent with the findings of Lin and Wu (2014), where the authors found that DC has an effect on the performance, resulting in improved SCA. Pertaining to H2 (DC to CC; $\gamma 21=0.94 ; p<0.000$ ), the findings revealed that there is a positive relationship between the dimensions of dynamic capability and core competency. This result is consistent with the findings of Lin and Wu (2014), where they found that DC has an effect on the competency, resulting in improved performance. Pertaining to H3a (CC to SCAM; $\gamma 21=0.91 ; p<0.000)$, the findings revealed that there is a positive relationship between the dimensions of core competency and SCAM. For the third hypothesis, H3b (CC to SCAC, $\beta 21=0.63$; $\mathrm{p}<0.000$ ), the results were significant, implying that there is a significant relationship between competency and SCAC. This result is supported 
by the findings of Terziovski and Dean (1998) where they found the intensity of customer management practices showed a positive association with SCAC outcomes. Pertaining to H3c (CC to SCAF; $\gamma 21=0.56 ; \mathrm{p}<0.000$ ), the findings revealed that there is a positive relationship between the competency and SCAF. For the third hypothesis, H4a (SCAM to SCAF, $\beta 21=0.62 ; \mathrm{p}$ $<0.000$ ), the results were significant, implying that there is a significant relationship between SCAM and SCAF. Pertaining to H4b (SCAC to SCAF; $\gamma 21=0.81 ; \mathrm{p}<0.000$ ), the findings revealed that there is a positive relationship between the dimensions of core competency and SCAM. This result is quite similar to Samat et al. (2006) study on the Malaysian service firms, where the information and communication has the greatest impact on service quality followed by other quality management practices such as customer focus, continuous improvement and empowerment. This result is consistent with the previous studies of Chang and Chen (1998) and Camarero (2007), where they found the market orientation has a positive relationship with service quality.

Table 4: Standardized path coefficients

\begin{tabular}{lccl}
\hline Hypotheses & Estimate & $\mathrm{p}$ & Remarks \\
\hline $\mathrm{H}_{1 \mathrm{a}}$ & 0.67 & $<0.000$ & Supported \\
$\mathrm{H}_{1 b}$ & 0.69 & $<0.000$ & Supported \\
$\mathrm{H}_{2}$ & 0.94 & $<0.000$ & Supported \\
$\mathrm{H}_{3 \mathrm{a}}$ & 0.91 & $<0.000$ & Supported \\
$\mathrm{H}_{3 b}$ & 0.63 & $<0.000$ & Supported \\
$\mathrm{H}_{3 \mathrm{c}}$ & 0.56 & $<0.000$ & Supported \\
$\mathrm{H}_{4 \mathrm{a}}$ & 0.62 & $<0.000$ & Supported \\
$\mathrm{H}_{4 b}$ & 0.81 & $<0.000$ & Supported \\
\hline
\end{tabular}

\section{DISCUSSION}

The empirical findings of this study are crucial to SCA and the key factors affecting it. From theoretical viewpoint, this study has undoubtedly contributed to the existing literature by providing a better understanding on the proposed structural relationships between SCA and key factors affecting it, where the structural relationship between constructs can be determined using SEM, which is superior to regression analysis. As far as the proposed structural model is concerned, this study offers some evidence for a positive effect of KBV, RBV, DC and CC practices on SCA. From a managerial perspective, the findings of the current study guide the banks to a better understanding of the importance of factors affecting on SCA in their managerial actions in becoming a truly market, customer and financial center. Hence, it is imperative for service providers to devote more attention to embrace these factors as a vital management tool for improving competitiveness. In a view of the highly competitive service environment, service practitioners should emphasize KBV, RBV, DC and CC as feasible change management tools to achieve a greater degree of SCA within their banks. Consequently, banks should constantly monitor the competitive service markets and response to change better than their rivals do. Furthermore, this study shows that the role of customer orientation has expanded and contributed to SCA. Hence, customer orientation practitioners should take full advantage of customer management to enhance the SCA. In doing so, top management must ensure a close cooperation and coordination among component of customer orientation in meeting the ever-changing customer needs. From the methodological perspective, the hypotheses formulated were measured and tested using the SEM approach. This method 
proved to be superior to regression analysis. Firstly, while SEM approach supplies statistical competency and provides a definite method to deal with multiple relationships simultaneously, multiple regression analysis does not. Secondly, as SEM is capable of testing the relationships comprehensively, it has moved from exploratory factor analysis to confirmatory factor analysis. Thirdly, the unobserved concepts and the measurement error in the estimation process are also taken into the account with the use of the SEM practice (Kline, 1998). Given the many advantages of SEM, coupled with the support of many researchers stating that such an approach is a useful methodological assessment tool for many measurement models (Boolen, 1989; Joreskog and Sorbom, 1993; Jimenez-Jimenez and Martinez-Costa, 2009), SEM was chosen to test the structural relationships between the four constructs.

This study empirically contributes to the attributes of KBV, RBV, DC and CC that can be seen on SCA in three areas of market, costumer and finance. From the analysis, it was shown that all the factors contribute significantly and positively to SCA. Moreover, implementation of sustainable competitive advantage of customer and market can improve the SCA of the Mellat bank. Findings are consistent with the studies performed by Lin and Wu (2014), which supported the strong positive relationship between organizational resources and capabilities and SCA since dynamic capabilities can mediate the firm's VRIN resources to improve performance and reach sustainable competitive advantage. Furthermore, Stephen (2007) findings about DC principles which serve as an apparatus for a company to achieve CC and SCA have also been supported by our study. Once practices of sustainable competitive advantage of market oriented are in place, market needs can be identified easily and marketing strategy can be further improved, creating values for the customers and accordingly, increase company profits. In other words, market-centered banks have the ability to understand their market targets better. They are more committed to provide premium service quality to their customers. And also, their efforts can lead to the provision of high quality service, which will then result in enhanced company performance. Generally, market-centered service firms are better able to meet the needs and expectations of their customers by providing superior service quality. In summary, when dimensions of sustainable competitive advantage of customer are present in the bank, banks will be prompt, proper and reliable, thus enhances the assurance of the bank services to the customers. Consequently, increase their profits and productivity.

\section{References}

Agha, S., Alrubaiee, L. and Jamhour, M. (2012). Effect of Core Competence on Competitive Advantage and Organizational Performance, International Journal of Business and Management, 7 (1), 192-204.

Akroush, M. and Al-Mohammad, S. (2010). The effect of marketing knowledge management on organizational erformance: An empirical investigation of the telecommunications organizations in Jordan, International Journal of Emerging Markets, 5 (1), 38-77.

Anderson, J. C. and Gerbing, D. W. (1988). Structural equation modeling in practice: a review and recommended two-step approach, Psychological Bulletin, 103, 411-23.

Amini, A., Darani, M., Afshani, M. and Amini, Z. (2012). Effectiveness of marketing strategies and corporate image on brand equity as a sustainable competitive advantage, Interdisciplinary Journal of Contemporary Research in Business, 4 (2), 192-205.

Bani, H. J. S., and AL-Hawary, F. (2009). The Impact of Core Competences on Competitive Advantage: Strategic Challenge. International Bulletin of Business Administration, 6, 93-104.

Barchan, M. (1998). Knowledge for business growth: how Celemi ensures strategic gains by measuring intangible assets, Knowledge Management Review, 3 (4), 13-15.

Barney, J. B. (1986). Types of competition and the theory of strategy: Toward an integrative framework", Academy of Management Review, 11 (4), 791-800. 
Barney, J. B. (1991). Firm resources and sustained competitive advantage, Journal of Management, 17 (1), 99-120.

Barney, J. B. (2001). Is the resource-based view a useful perspective for strategic management research. Academy of Management Review, 26 (1), 41-56.

Bogner, W. H., Thomas, H. and McGee, J. (1999). Competence and Competitive Advantage: Towards a Dynamic Model. British Journal of Management, 10, 275-290.

Bhatt, G. D. (2001) Knowledge management in organizations: Examining the interaction between technologies, techniques and people. Journal of Knowledge Management, 5 (1), 68-75.

Bollen, K. A. (1989). A new incremental fit index for general structural equation models. Sociological Methods and Research, 17 (3), 303-316.

Boolen, K.A. (1989), Structural Equations with Latent Variables, Wiley, New York, NY.

Bagozzi, R. P. and Yi, Y. (1988). On the evaluation of structural equation models. Journal of Academy of Marketing Science, 16, 74-94.

Browne, M. W. and Cudeck, R. (1992). Alternative Ways of Assessing Model Fit. Sociological Methods Research, 21, 230-58.

Carlos, M. P., Sousa, E. R. and Fernando, L. (2010). The Key Role of Managers' Values in Exporting: Influence on Customer Responsiveness and Export Performance. Journal of International Marketing, 18, 1-19.

Camarero, C. (2007). Relationship orientation or service quality?: What is the trigger of performance in financial and insurance services?. The International Journal of Bank Marketing, 25 (6), 406-426.

Campbell, D. T. (1959). Convergent and discriminant validation by the multitrait-multimethod matrix.

Psychological Bulletin, 56 (2), 81-105.

Chang, T.Z. and Chen, S.J. (1998), Market orientation, service quality and business profitability: a conceptual model and empirical evidence. Journal of Services Marketing, 12 (4), 246-264.

Christensen. C. M. (2001). The past and future of competitive advantage. MIT Sloan Management Review, 42, 105119.

Collinson, S. (1999). Knowledge management capabilities for steel makers: a British-Japanese corporate alliance for organizational learning. Technology Analysis \& Strategic Management, 11 (3), 337-358.

Davenport, T. H., Long, D. W. and Beers, M. C. (1998). Successful knowledge management projects. Sloan Management Review, 39 (2), 43-57.

Dierickx, J. and Cool, K. (1989), Asset stock accumulation and sustainability of competitive advantage, Management Science, 35 (12), 1504-1511.

Drucker, P. F. (1993). Managing for the future: The 1990s and beyond, Truman Talley, New York.

Easterby, S, M., Lyles, M. A. and Peteraf, M. A. (2009). Dynamic capabilities: current debate and future directions. Journal Mana, 20, 1-8.

Eisenhardt, K. M. and Martin, J. A. (2000). Dynamic capabilities: what are they? Strategic Management Journal, 21, $1105-1121$.

Evans, M., Jamal, A. and Foxall, G. (2009), Consumer Behavior, West Sussex, England: John Wiley \& Sons Ltd.

Foerstl, K., Reuter, C., Hartmann, E. and Blome, C. (2010). Managing supplier sustain- ability risksina dynamically changing environment - sustainable supplier management in the chemical industry. Journal of Purchasing and Supply Management, 16, 118-130.

Fornell, C. and Larcker, D. F. (1981). Evaluating structural equation models with unobservable variables and measurement error". Journal of Marketing Research, 18, 39-50.

Gupta, S., Woodside, A., Dubelaar, C. and Bradmore, D. (2009). Diffusing knowledge-based core competencies for leveraging innovation strategies: Modeling outsourcing to knowledge process organizations (KPOs) in pharmaceutical networks. Industrial Marketing Management, 38 (2), 219-227. 
Jafari, M. and Rezaee, F. (2014). The effect of resource based view on sustainable compatibility advantage. Management Science Letters, 4, 2537-2554.

Jang, S., Hong. K., Bock, G. W. and Kim, I. (2002). Knowledge management and process innovation: The knowledge transformation path in Samsung SDI. Journal of Knowledge Management, 6, 479-485.

Javidan, M. (1998), Core Competence: What Does it Mean in Practice, Long Range Planning, 31 (1), 60-70.

Jimenez, J. D. and Martinez, C. M. (2009). The performance effect of HRM and TQM: a study in Spanish organizations. International Journal of Operations and Production Management, 29 (12), 1266-1289.

Johnson, G., Scholes, K. and Whittington, R. (2008). Exploring corporate strategy; Text and Cases, FT Prentice Hall, Pearson Education.

Jones, G. R., and Hill, C. W. L. (2013). Theory of strategic management with cases, Canada: South- Western, Cengage Learning.

Josiah, A. (2013). Business leverages on strategic information systems in Nigeria. International Journal of Learning \& Development, 3 (1), 212-220.

Joreskog, K. G. and Sorbom, D. (1993). Structural Equation Modeling with SIMPLIS Command Language, Lawrence Erlbaum, Hillsdale, NJ.

Kline, R.B. (1998). Principles and Practice of Structural Equation Modeling, Guilford Press, New York, NY.

Kline, R.B. (2005). Principles and Practice of Structural Equation Modeling, 2nd ed. Guilford Press, New York.

Kogut, B. and Zander, U. (1996). What firms do? Coordination, identity, and learning. Organization Science, 7 (5), 502-518.

Kozlenkova, I. V., Samaha, S. A. and Palmatier, R. W. (2014). Resource-based theory in marketing, Journal of the Academy of Marketing Science, 42 (1), 1-21.

Leonard, B. D. (1992). Core capabilities and core rigidities: A paradox in managing new product development. Strategic Management Journal, 13, 111-125.

Li, J. J. and Zhou, K. Z. (2010). How Foreign Firms Achieve Competitive Advantage in the Chinese Emerging Economy: Managerial Ties and Market Orientation. Journal of Business Research, 63, 856-862.

Lin, Y. and Wu, L. Y. (2014). Exploring the role of dynamic capabilities in firm performance under the resourcebased view framework. Journal of Business Research, 67, 407-413.

Ljungquist, U. (2008). Specification of core competence and associated components: A proposed model and a case illustration", European Business Review, 20 (1), 73-90.

Makkonen, H., Pohjola, M., Olkkonen, R. and Koponen, A. (2014). Dynamic capabilities and firm performance in a financial crisis. Journal of Business Research, 67, 2707-2719.

Makadok, R. (2001). Toward a synthesis of the resource-based and dynamic-capability views of rent creation. Strategic Management Journal, 22 (5), 387-401.

Massey, A., Montoya. M. and Driscoll, T, (2002). Knowledge management in pursuit of performance: insights from Nortel networks. MIS Quarterly, 26 (3), 269-289.

Marakas G. M. (1999). Decision support systems in the twenty-first century, Illustrated. Upper Saddle River, N.J., Prentice Hall. Pennsylvania State University.

Michailova, S. and Husted, K, (2003). Knowledge sharing in Russian companies with western participation. Management International, 6 (2), pp. 19-28.

Mathiassen, L. and Vainio, A. M. (2007). Dynamic capabilities in small software firms: a senseand-respond approach. IEEE Transactions on Engineering Management, 54, 522-538.

Menon, A. G. (2008). Revisiting Dynamic Capability, IIMB Management Review, 20, 22-33.

Menon, A. G. and Mohanty, B. (2008). Towards a theory of dynamic capability for firms. Paper presented at sixth International Conference on Management (AIMS), 28-31 Desember, and College of Business-MMBA of Houston. 
Rezaee, F. \& Jafari, M. (2016). Key Determinants of Success to Achieve Sustainable Competitive Advantage (SCA). Archives of Business Research, $4(6), 351-375$

Nonaka, I. and Toyama, R. (2007). Strategic management as distributed practical wisdom (phronesis). Industrial and Corporate Change, 16, 371-394.

Nunnally, J.C. and Bernstein, I.H. (1994), Psychometric Theory, McGraw-Hill, New York, NY.

Pearce, J. A. and Robinson. R. B. (2000), Strategic management: formulation, Implementation, and Control, Irwin Mc Graw- Hill, Boston, MA.

Peteraf, M. A. (1993). The cornerstones of competitive advantage: A resource-based view. Strategic Management Journal, 14 (3), 179-191.

Porter. M. E. (1987). From competitive advantage to corporate strategy. Harvard business riview, 65, 43-59.

Razali, N. M, and Wah, Y. B. (2011). Power comparisons of Shapiro-Wilk, Kolmogorov-Smirnov, Lilliefors and Anserson-Darling tests. Journal Stat Model Anal, 2 (1), 21-33.

Reed, R. and Defillippi, R. (1990). Casual ambiguity, barrirs to imitation, and sustainable competitive advantage. Academy of Management Review, 15, 88-102.

Rezaee, F. and Jafari, M. (2015). The effect of marketing knowledge management on sustainable competitive advantage: Evidece from banking industry. Accounting, 1 (2), 69-88.

Rezaee, F and Jafari, M. (2016). Dynamic capability in an under-researched cultural environment. Management Science Letters, 6 (2), 177-192.

Rijamampianina, R., Abratt, R., and February, Y. (2003). A framework for concentric diversification through sustainable competitive advantage, Management Decision, 41 (4), 362-371.

Rowley, J. (2005). Customer knowledge management or consumer surveillance. Global Business and Economics Review, 7 (1), 100-110.

Samat, N., Ramayah, T. and Saad, N.M. (2006). TQM practices, service quality, and market orientation: some empirical evidence from developing country. Management Research News, 29 (11), 713-728.

Seetharaman, A., Nadzir, Z. A. and Gunalan, S. (2001). A conceptual study on brand valuation. Journal of Product and Brand Management, 10 (4), 243-256.

Stephen, N. (2010). Dynamic Capabilities, Organizational Citizenship Behavior and Managed Performance in Business, Technical and Vocational Education Training Institutions. Working paper [HD10/11135U], Human resource Management, Makerere University.

Srivastava, Sh. (2005). Managing Core Competence of the Organization. Vikalpa, 30 (4), 49-68.

Talaja, A. (2012). Testing VRIN framework: resource value and rareness as sources of competitive advantage and above average. Management: Journal of Contemporary Management, 17 (2), pp. 51-64.

Tanriverdi, H. (2005). Information technology relatedness, knowledge management capability and performance of multi business firms. MIS Quarterly, 29 (2), 311-334.

Teece, D. J. (2007). Explicating dynamic capabilities: thenatureand micro foundations of (sustainable) enterprise performance. Strategy Management Journal, 28, 1319-1350.

Teece, D. J., Pisano, G. and Shuen, A. (1997). Dynamic capabilities and strategic management. Strategic Management Journal, 18, 509-33.

Thompson, A., Peteraf, M. A., Gamble, J. E. and Strickland, A. J. (2012). Crafting and executing strategy concepts and readings, McGraw Hill Irwin: New York.

Trung, T. D. H. (2014). Obtaining sustainable competitive advantage from customer loyalty: A perspective of marketing-mix strategy and corporate social responsibility. Working paper. Department of international business administration, College of Business Chinese Culture University.

Terziovski, M. and Dean, A. (1998). Best predictors of quality performance in Australian service organizations. Managing Service Quality, 8 (5), 359-366.

Villalonga, B. and Amit, R. (2006). How do family ownership, management, and control affect firm value? Journal of Financial Economics, 80 (2), 385-417. 
Winter, S. G. (2003). Understanding dynamic capabilities. Strategy Management Journal, 24, 991-95.

Wang, C. and Ahmed, P. (2007). Dynamic capabilities: a review and research agenda. International Journal of Management Reviews, 9, 31-51.

Zahra, S.A. and George, G. (2002). Absorptive capacity: a review, reconceptualization, and extension. Academy of Management Review, 27, 185-203.

Zeleny, M. (2005). Knowledge-information circulation through the enterprise: forward to the roots of knowledge management. Lecture Notes in Computer Science, 3327, 22-33.

Zollo, M. and winter, S. G. (2002). Deliberate Learning and the Evolution of Dynamic Capabilities. Organization Science, 13, 39-51. 